\title{
Infección pulmonar no invasora por Scedosporium apiospermum
}

\author{
Rodrigo Cruz, Manuel Barros y Mirtha Reyes
}

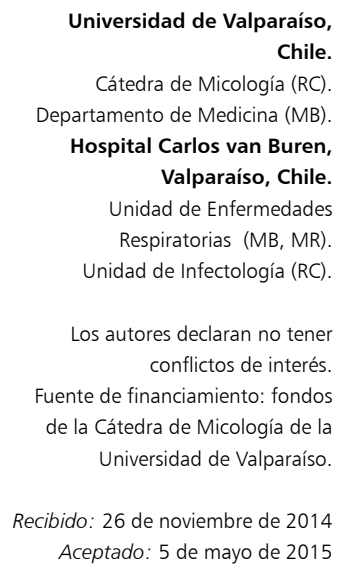

Universidad de Valparaíso

Chile.

Cátedra de Micología (RC)

Departamento de Medicina (MB) Hospital Carlos van Buren,

Valparaíso, Chile.

Unidad de Enfermedades

Respiratorias (MB, MR)

Unidad de Infectología (RC).

Los autores declaran no tener conflictos de interés. Fuente de financiamiento: fondos de la Cátedra de Micología de la Universidad de Valparaíso.

Recibido: 26 de noviembre de 2014 Aceptado: 5 de mayo de 2015

Correspondencia a:

Rodrigo Cruz Choappa rcruzchoappa@gmail.com

\section{Introducción}

E 1 diagnóstico de las infecciones pulmonares por hongos filamentosos ha aumentado en los últimos años, tanto en pacientes inmunocomprometidos como en aquellos con respuesta inmunológica normal, pero con factores de riesgo como enfermedad pulmonar obstructiva crónica (EPOC), bronquiectasias o fibrosis pulmonar ${ }^{1,2}$. Estas infecciones se consideran invasoras si comprometen el parénquima pulmonar y no invasora si el hongo crece en forma saprófita en bronquios, bronquiectasias, cavernas o lesiones crónicas pulmonares ${ }^{2}$.

La mayoría son producidas por especies del género Aspergillus, especialmente Aspergillus fumigatus. Sin embargo, otros géneros como Fusarium, Acremonium o Scedosporium spp. se aíslan con cierta frecuencia ${ }^{3}$.

El género Scedosporium está integrado por un grupo de hongos oportunistas ambientales de distribución mundial, donde las especies clínicamente más relevantes son Scedosporium apiospermum y S. prolificans ${ }^{3-5}$.

Scedosporium apiospermum se ha descrito como el agente etiológico del pie de madura, micetoma, de infecciones pulmonares invasoras y no invasoras, además de otras localizaciones como artritis séptica, osteomielitis, infecciones oftálmicas, sinusitis, meningitis, abscesos cerebrales, endocarditis e infecciones diseminadas ${ }^{5}$. El tratamiento de las infecciones por este hongo es difícil, ya que presenta resistencia a varios de los antifúngicos habitualmente utilizados ${ }^{6}$.

Se describe el caso de una infección pulmonar no invasora por $S$. apiospermum. Además se realiza una revisión de su patogenia, formas clínicas de presentación, diagnóstico y tratamiento actual.

\section{Caso clínico}

Mujer de 67 años de edad, con antecedentes de tuberculosis pulmonar tratada hacía más de 40 años y una limitación crónica del flujo aéreo (LCFA), secundario a secuelas de tuberculosis. No fumaba tabaco y tenía antecedente de haber trabajado en labores agrícolas. Estaba en tratamiento por una hipertensión arterial; refería atopia, y reacción alérgica a sulfas y amoxicilina. Había cursado con infecciones respiratorias a repetición y exacerbaciones frecuentes durante los últimos cinco años, por lo que estaba en tratamiento con salmeterol/ fluticasona $(25 / 250 \mathrm{mcg})$, dos inhalaciones dos veces al día y salbutamol en caso de crisis obstructivas.

Fue derivada al policlínico de enfermedades respiratorias de nuestro hospital por presentar disnea progresiva, tos productiva persistente y hemoptisis intermitente hacía ya un año. Su evaluación funcional demostró un volumen espiratorio forzado $\left(\mathrm{VEF}_{1}\right)$ disminuido a $640 \mathrm{ml}(33 \%$ de valor esperado) y capacidad vital forzada a $1.440 \mathrm{ml}$ $(55 \%)$ sin cambios con uso de broncodilatador. Estos valores fueron similares a los obtenidos en espirometrías realizadas hacía 10 años atrás. Una radiografía de tórax demostró disminución de volumen pulmonar, de predominio en el hemitórax derecho. Una TAC de tórax mostró múltiples cavernas y bronquiectasias bilaterales, focos de atelectasias de aspecto cicatricial, signos de árbol en brote y bolas fúngicas en el interior de algunas de las cavidades (Figura 1). Se realizó una fibrobroncoscopia para estudio microbiológico, describiéndose abundante secreción purulenta adherente en todo el árbol traqueo-bronquial. Durante el procedimiento la paciente presentó un episodio de disnea, desaturación de oxígeno, crisis hipertensiva y compromiso del estado general. Fue asistida y aunque 
logró mejoría, fue necesaria su internación en la Unidad de Emergencia.

A su ingreso estaba lúcida, con presión arterial: $160 / 100 \mathrm{mmHg}$, taquicardia de 130 pulsaciones por minuto, taquipnea de 28 respiraciones por minuto y oximetría de pulso de $90 \%$ con aire ambiental. Al examen físico pulmonar presentaba murmullo pulmonar disminuido globalmente, abundantes crepitaciones y sibilancias espiratorias difusas. Dentro de los exámenes de laboratorio destacó un recuento de leucocitos de 15.200 céls $/ \mathrm{mm}^{3}$, PCR $15 \mathrm{mg} / \mathrm{dl}(\mathrm{VN}<0,5 \mathrm{mg} / \mathrm{dl})$ y hematocrito $37,4 \%$. Se indicó oxigenoterapia por mascarilla Venturi al 28\%, nebulizaciones con salbutamol y kinesioterapia respiratoria. Además se inició tratamiento antimicrobiano con ceftriaxona i.v. en espera del estudio microbiológico. En las muestras de lavado broncoalveolar (LBA), la tinción de Gram mostró abundante cantidad de cocáceas grampositivas y la tinción de Gomori-Grocott, gran cantidad de hifas septadas en ángulo dicotómico. En la tinción de Ziehl-Neelsen no se observaron bacilos alcohol ácido resistentes. En el cultivo bacteriano hubo desarrollo de Staphylococcus aureus sensible a oxacilina en concentración de $1 \times 10^{3} / \mathrm{ml}$ y en el cultivo de hongos hubo abundante desarrollo de $S$. apiospermum.

Se inició tratamiento con itraconazol vía oral 200 $\mathrm{mg}$, dos veces al día, sin cobertura anti-estafilocóccica. Evolucionó con disminución de la disnea, hemoptisis y de los índices de actividad inflamatoria, por lo que se dio alta hospitalaria. Sin embargo, desde la sexta semana volvió a presentar tos con broncorrea abundante. Se solicitaron nuevos cultivos de expectoración, los cuales se informaron con abundante desarrollo de $S$. apiospermum, sin crecimiento bacteriano y con baciloscopias negativas. Se cambió tratamiento a voriconazol vía oral, $200 \mathrm{mg}$ dos veces día. No se utilizó dosis de carga ni se pudo realizar medición de concentraciones plasmáticas. Completó 16 semanas de tratamiento, con buena respuesta clínica y cultivos de expectoración sin desarrollo de hongos. Controlada seis meses después de completar la terapia, se encontraba con escasa tos, sin broncorrea ni hemoptisis y con disminución significativa de la disnea, lo que le había permitido reiniciar sus actividades habituales. En el TAC pulmonar de control se observó una disminución parcial de las lesiones (Figura 2); sin embargo, clínicamente estaba en buenas condiciones generales y sin recidiva del cuadro respiratorio.

\section{Estudio micológico}

Las muestras de LBA y de expectoración fueron sembradas en agar Sabouraud a $37^{\circ} \mathrm{C}$, donde hubo abundante desarrollo de un hongo filamentoso septado, inicialmente de color blanco, anelídico, con ameroconidios clavados abundantes, de base trunca y paredes lisas. Posteriormente fue traspasado a agar papa dextrosa (PDA), donde a $25^{\circ} \mathrm{C}$

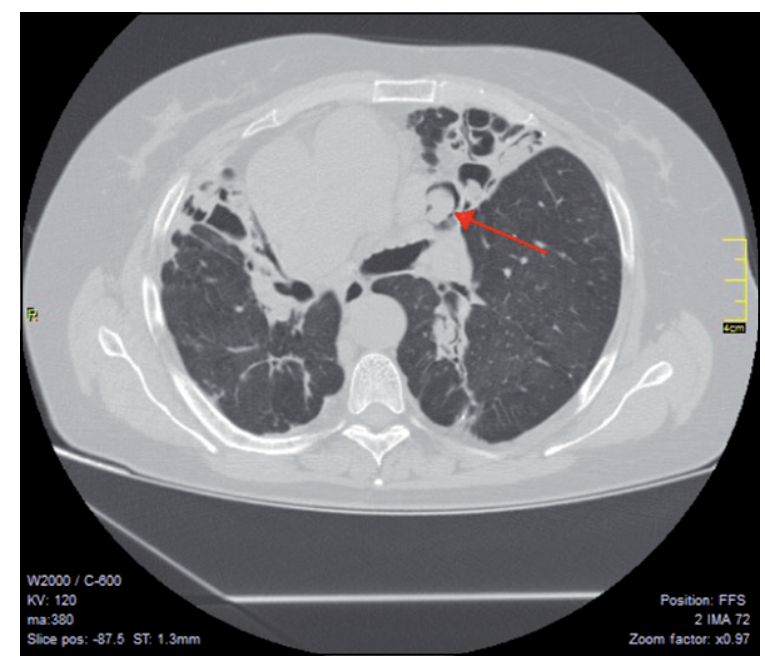

Figura 1. TAC pulmonar con cavernas, bronquiectasias y bola fúngica.

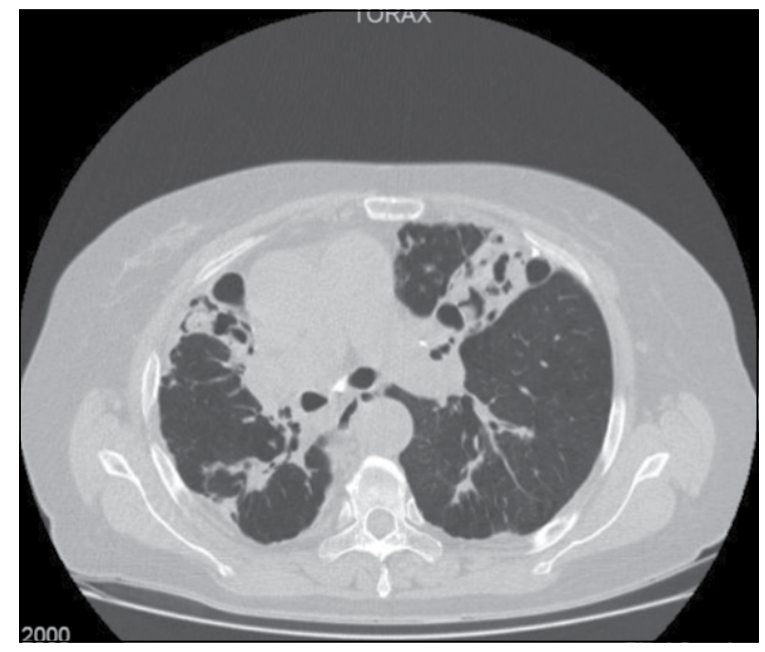

Figura 2. TAC pulmonar con disminución de las lesiones.

las colonias crecieron hasta $50 \mathrm{~mm}$ en 14 días, de color blancas grisáceas con un reverso gris (Figura 3), con células conidiógenas anelídicas cilíndricas hialinas que nacían de hifas indiferenciadas únicas y ramificadas, y con numerosos conidios café pálidos, clavados, redondeados en un extremo, con base trunca, solitarios o en pequeños grupos, de 4-9 de ancho x 6-10 $\mu \mathrm{m}$ de largo (Figura 4). A las tres semanas de cultivo apareció el sinanamorfo Graphium en los extremos de las colonias, con conidióforos cilíndricos, café oliva, lisos, que terminaba en un racimo de células conidiógenas anelídicas delgadas, con conidios subhialinos o café pálidos reunidos en substancia mucoide, ampliamente clavados, 6-12 x 3,5-4 $\mu \mathrm{m}$. Todo lo anterior confirmó la identificación de S. apiospermum. 
Figura 3. Colonia de Scedosporium apiospermum en agar papa-dextrosa a los 14 días.
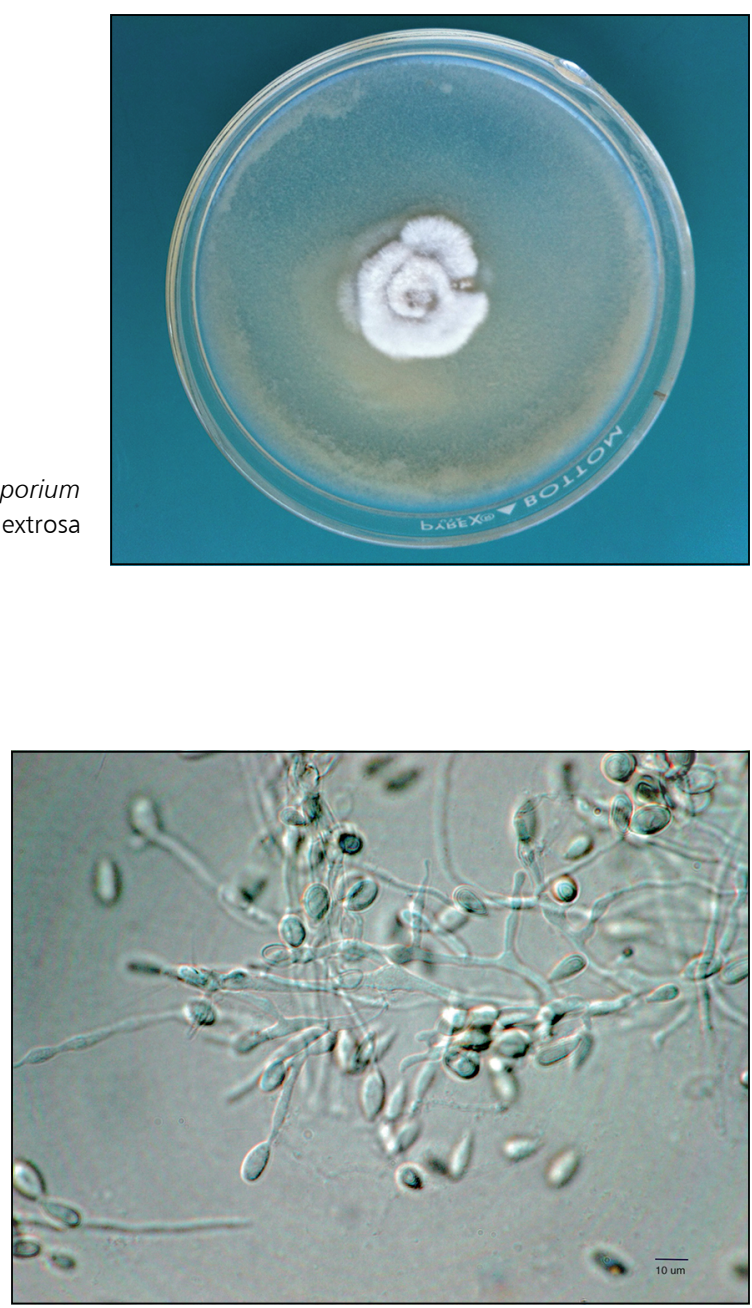

Figura 4. Células conidiógenas cilíndricas anelídicas, hialinas, con conidios clavados redondeados en un extremo, con base trunca, de 4-9 de ancho $x$ 6-10 $\mu \mathrm{m}$ de largo. 100X.

scedosporiasis broncopulmonar alérgica (SBPA) y la bola fúngica o fungoma ${ }^{5,11}$. La formación de un fungoma está determinada por la presencia de cavidades o bronquiectasias pulmonares secundarias a tuberculosis, sarcoidosis o fibrosis quística, las cuales por inhalación pueden ser colonizadas por conidios de distintas especies ambientales $^{5-11}$. En nuestra paciente, la colonización ocurrió tanto en el árbol traqueo-bronquial como en las cavernas y bronquiectasias secundarias a una tuberculosis pulmonar antigua.

La colonización por lo general conduce al desarrollo de un conglomerado de hifas entrelazadas con moco y detritus celulares, estimulando la inflamación crónica y respuesta del tejido de granulación vascular, además del engrosamiento de las paredes de las cavidades y la pleura adyacente ${ }^{11-12}$. En nuestra paciente no se realizó biopsia de pulmón para determinar si existía invasión del parénquima; sin embargo, considerando los factores de riesgo, las imágenes en el TAC y los cultivos, se consideró como una enfermedad no invasora.

Clínicamente los pacientes presentan tos persistente con broncorrea, hemoptisis, fiebre y compromiso del estado general ${ }^{11,12}$. En estos casos siempre se debe descartar una tuberculosis pulmonar, colonización por otros hongos e infecciones bacterianas. Nuestra paciente presentó todos los síntomas y signos descritos anteriormente, se descartó una tuberculosis activa e infección por otros hongos más frecuentes como Aspergillus spp. El fungoma pulmonar da lugar a una imagen en la TAC caracterizada por nódulos intracavitarios, los que pueden ser únicos o múltiples dependiendo del tamaño de las cavernas ${ }^{12}$.

Al igual que las infecciones por Aspergillus spp., el tratamiento quirúrgico debe ser planteado con fines curativos si las condiciones generales y la función pulmonar lo permiten, asociándose a una alta mortalidad (7-23\%) y morbilidad $^{13}$. En nuestra paciente, el extenso compromiso de ambos pulmones y la deteriorada función pulmonar basal impidieron su realización.

El tratamiento médico presenta algunos desafíos, ya

Las especies pertenecientes al género Scedosporium se consideran consistentemente termo-tolerantes (37$42^{\circ} \mathrm{C}$ ), con la capacidad de crecer en distintos tipos de sustratos, tales como suelos, vegetales y aguas en climas temperados ${ }^{4}$. Scedosporium apiospermum se encuentra distribuido universalmente y la temperatura óptima de crecimiento es entre $30-37^{\circ} \mathrm{C}^{4,5}$. Existe una variedad de infecciones descritas para este agente, destacando las infecciones invasoras pulmonares en pacientes inmunocomprometidos y las no invasoras en pacientes con daño pulmonar estructural previo ${ }^{5-7}$. En Chile y Latinoamérica se han reportado casos de infecciones no invasoras por $S$. apiospermum, tanto en localización sinusal como pulmonar $^{8-10}$.

La enfermedad fúngica pulmonar no invasora está constituida por la colonización traqueo-bronquial, la que $S$. apiospermum por lo general presenta resistencia a anfotericina B, fluconazol, ketoconazol, flucitocina y terbinafina, y es sensible a voriconazol e itraconazol ${ }^{5,6}$. Sin embargo, se sugiere que en infecciones por las distintas especies del género se realice estudio de susceptibilidad con CIM ya que pueden existir cepas con mayor resistencia ${ }^{14}$.

Nuestra paciente fue tratada inicialmente con itraconazol debido a que no se contaba en ese momento con otro antifúngico sistémico con actividad contra S. apiospermum. Posteriormente se obtuvo una buena respuesta clínica y microbiológica con voriconazol, con el cual completó 16 semanas. Entre las posibles explicaciones para el fracaso de la terapia con itraconazol, se pueden mencionar su absorción errática, con niveles plasmáticos subterapéuticos en muchos pacientes, a diferencia de vori- 
conazol que tiene una biodisponibilidad superior a $90 \%{ }^{15}$. Por otra parte, no se encuentra bien definida la duración de tratamiento de estas infecciones, por lo que se debe analizar cada caso ${ }^{13}$. En nuestra paciente, se necesitaron 16 semanas de terapia para obtener una buena respuesta clínica y micológica.

Al igual que en la enfermedad fúngica invasora, en aquellas infecciones no invasoras es fundamental identificar la especie para iniciar el tratamiento adecuado y en el caso del fungoma plantear la posibilidad quirúrgica cuando ello sea factible.

\section{Resumen}

Reportamos el caso clínico de una infección pulmonar no invasora por Scedosporium apiospermum en una mujer de 67 años de edad, con bronquiectasias y cavernas pulmonares secundarias a una tuberculosis. El diagnóstico se realizó con la TAC pulmonar y cultivos de lavado bronquial. La paciente fue tratada inicialmente con itraconazol oral por seis semanas sin respuesta y luego voriconazol vía oral por 16 semanas, con una buena respuesta clínica.

\section{Referencias bibliográficas}

1.- Ascioglu S, Rex J H, De Pauw B, Bennett J E, Bille J, Crokaert F, et al. Defining opportunistic invasive fungal infections in immunocompromised patients with cancer and hematopoietic stem cell transplants: an international consensus. Clin Infect Dis 2002; 34: 7-14

2.- Cruz R, Vieille P, Fuentes D, Ponce E, Piontelli E. Frecuency of pulmonary mycoses determined by analyzing lung secretion samples. Rev Med Chile 2012; 140: 595-601.

3.- Cooley L, Spelman D, Thursky K, Slavin M. Infection with Scedosporium apiospermum and S. prolificans, Australia. Emerg Infect Dis 2007; 13: 1170-7.

4.- Piontelli E. El complejo Pseudallescherial Scedosporium y taxas afines en la rutina del laboratorio micológico clínico. Boletín Micológico 2012; 27 (2): 65-77.

5.- Guarro J, Kantarcioglu A S, Horré R, Rodríguez-Tudela J L, Cuenca Estrella M, Berenguer J, et al. Scedosporium apiospermum: changing clinical spectrum of a therapyrefractory opportunist. Med Mycol 2006; 44: 295-327.

6.- Solé A. Infección diseminada por Scedosporium apiospermum en un receptor de trasplante pulmonar unilateral. Rev Iberoam Micol 2011; 28: 139-42.

7.- Montagna M T, Lovero G, Coretti C, Martnelli D, Delia M, De Giglio O, et al. SIMIFF study: Italian fungal registry of mold infections in hematological and non-hematological patients. Infection 2014; 42: 141-51.

8.- Chanqueo L, Gutiérrez C, Tapia C, Silva V, Razeto L, Misad C. Infección rinosinusal por Scedosporium apiospermum en un hospedero inmunocompetente. Rev Chilena Infectol 2009; 26: 453-6.

9.- Somocurcio J, Sotomayor A, Álvarez G, Acurio V, Casquero J, Luna T. Micetoma pulmonar por Scedosporium sp., reporte de dos casos. Rev Peru Med Exp Salud Pública 2009; 26: 395-99.

10.- López-Martínez R, Méndez-Tovar L J, Bonifaz A, Arenas R, Mayorga J, Welsh O, et al.
Actualización de la epidemiología del micetoma en México. Revisión de 3933 casos. Gac Med Mex 2013; 149: 586-92.

11.- Kantarcioglu A S, de Hoog G S, Guarro J. Clinical characteristics and epidemiology of pulmonary pseudallescheriasis. Rev Iberoam Micol 2012; 29: 1-13.

12.- Cortez K J, Roilides E, Quiroz-Telles F, Meletiadis J, Antachopoulos C, Knudsen T, et al. Infections caused by Scedosporium spp. Clin Microbiol Rev 2008; 21: 157-97.

13.- Torales M, Martínez F, Bagattini J C. Aspergiloma pulmonar bilateral. Arch Med Int 2010; 32: 53-6.

14.- Lackner M, de Hoog G S, Verweij P E, Najafzadeh M J, Curfs-Breuker I, Klaassen C H, et al. Species-specific antifungal susceptibility patterns of Scedosporium and Pseudallescheria species. Antimicrob Agents Chemother 2012; 56: $2635-42$

15.- Dodds E. Pharmacology of Azole Antifungal Agents. En: Ghannoum M, Perfect J. Editors, Antifungal Therapy. New York, USA: Informa Healthcare Inc; 2010. Pág 199-218. 